IMECE2013-65080

\title{
EXERGY EFFICIENCY OPTIMIZATION FOR GAS TURBINE BASED COGENERATION SYSTEMS
}

\author{
Ana C. Ferreira \\ CGIT R\&D Center, University of Minho \\ Guimarães, Portugal \\ José C. Teixeira
CT2M R\&D Center University of Minho \\ CGIT R\&D Center, University of Minho \\ Guimarães, Portugal \\ Guimarães, Portugal
}

\author{
Manuel L. Nunes \\ CGIT R\&D Center, University of Minho \\ Guimarães, Portugal
}

\author{
Luís B. Martins \\ CT2M R\&D Center, University of Minho \\ Guimarães, Portugal
}

\begin{abstract}
Energy degradation can be calculated by the quantification of entropy and loss of work and is a common approach in power plant performance analysis. Information about the location, amount and sources of system deficiencies are determined by the exergy analysis, which quantifies the exergy destruction. Micro-gas turbines are prime movers that are ideally suited for cogeneration applications due to their flexibility in providing stable and reliable power. This paper presents an exergy analysis by means of a numerical simulation of a regenerative micro-gas turbine for cogeneration applications. The main objective is to study the best configuration of each system component, considering the minimization of the system irreversibilities. Each component of the system was evaluated considering the quantitative exergy balance. Subsequently the optimization procedure was applied to the mathematical model that describes the full system.

The rate of irreversibility, efficiency and flaws are highlighted for each system component and for the whole system. The effect of turbine inlet temperature change on plant exergy destruction was also evaluated. The results disclose that considerable exergy destruction occurs in the combustion chamber. Also, it was revealed that the exergy efficiency is expressively dependent on the changes of the turbine inlet temperature and increases with the latter.
\end{abstract}

Key-words: Small-scale CHP; High-Efficiency Exergy Analysis; Numerical Optimization.

\section{INTRODUCTION}

Cogeneration or Combined Heat and Power (CHP) production is the simultaneous production of electricity and useful thermal energy from a single primary energy source. Distributed generation systems, in small and micro-scale applications, are of increasing interest in the energy market, due to their great potential in primary energy savings and reduction of gas emissions. Such power plants can reach an overall efficiency in the range of $80-90 \%$, depending on the prime mover's technology and integration with the heat demand [1]. One of the target markets for CHP applications is the building sector. It is believed that the use of CHP power plants in buildings offers significant benefits to end-users because it is possible to generate income from selling electricity and also by reducing the primary energy consumption [2]. In Europe, cogeneration power plants are being designed to fulfill the thermal energy loads. These systems are adjusted to replace boilers (or other conventional thermal production systems) and, additionally, generate electricity for self-consumption (or feed into the grid).

Cogeneration technologies usually benefit from policies such as subsidized or guaranteed feed-in-tariffs. In 2006, the European Directive 2004/8/EC [3] established a framework for the promotion of high-efficiency cogeneration systems matching the useful heat demand. The directive sets a less restrictive legal scenario for the installation of cogeneration systems in addition to guaranteed revenues on its use. Several technologies such Internal Combustion Engines (ICE), Organic Rankine Cycles (ORC), Stirling engines, Fuel Cells or gas turbines are being applied to cogeneration systems, being the 
micro-gas turbines one of the most reported technologies in the literature [2,4-6]. Micro gas turbines (in the range of 25-250 $\mathrm{kW}_{\mathrm{e}}$ ) present several advantages when compared with other technologies for small-scale power generation. Their compact size, high specific power, small number of moving parts, low noise, multi-fuel possibilities, as well as, low emission make them attractive to cogeneration systems. The fuel options include natural gas, diesel, ethanol, and other bio-based liquids and gases [7].

The high temperature exhaust from gas turbine can be used to produce domestic hot water or space heating. Thus, in CHP applications, gas turbine power plants can reach an overall efficiency up to 85\%, based on LHV [8]. From the operational point of view, the Turbine Inlet Temperature (TIT) of current micro-turbines ranges from $1070 \mathrm{~K}$ to $1270 \mathrm{~K}$, due to limitations on material and construction. In addition, the compressor pressure ratio is relatively low, typically of about 4.0. Such limitations affect the system's electrical efficiency, which can be improved by using regeneration. Consequently, micro-turbines typically include an internal air pre-heater (regenerator) to recover part of the exhaust gases energy enhancing the plant electrical efficiency. Furthermore, the thermal energy from the exhaust gases is recovered to supply the heat demand. Finally, the competitiveness of this technology is mainly due to their relative low investment cost, which for micro turbine-based CHP applications is estimated to vary within the range of 1,000 to $1,700 € / \mathrm{kW}_{\mathrm{e}}[9,10]$.

Computational optimization algorithms are suitable for designing and testing a wide variety of real engineering problems. All the modeling techniques require the definition of an objective function and problem constraints, which confer physical significance to the problem.

One approach takes into account the thermodynamic aspects of the energy system as the basis for thermo-economic methodologies. The thermo-economic analysis can be divided in two different fields: (i) one focused on the cost flow analysis when the objective is the determination of cost generation and/or cost losses and (ii) another focused on the selection of the optimum operational conditions $[18,19]$.

Exergy analysis allows a complete thermodynamic assessment of energy conservation, by providing the appropriate tool to differentiate between energy losses to the environment and the internal irreversibility in the process [11]. The system's evaluation, based on the second law of thermodynamics, accounts for the exergy balance in the entire system and for each one of the components by assessing the amount of irreversibility that corresponds to the energy destruction $[12,13]$.

Exergy analysis has been used to determine the location and magnitude of energy destruction [14]. Different approaches using exergy analysis have been proposed in the literature. Ahmadi and Dincer [15] report a comprehensive thermodynamic and exergo-economic modeling of a Gas Turbine (GT) power plant, aiming to validate the thermodynamic model through a multi-objective optimization. The authors reported that the combustion chamber is the component with the highest irreversibility rate. Erdil [16] analyzed and optimized the exergy output rate and exergy efficiency performance of an irreversible Carnot cycle cogeneration plant with heat resistance, heat leakage and internal irreversibility. Bilgen [12] performed exergetic and engineering analyses of gas turbine-based cogeneration plants consisting of a gas turbine, heat recovery steam generator and steam turbine. Rodriguez-Toral and co-authors [17] presented an equation-oriented mathematical model for the optimization of combined cycle cogeneration plants using the sequential quadratic programming.

The main objective of this work is the development of an optimization mathematical model applied to a small-scale CHP system, based on a micro-gas turbine as prime mover, running with Natural Gas.

In a previous work, the system was optimized by applying the first law of thermodynamics [20]. In this paper the first and second laws are used to develop an exergy balance for each one of the plant components and integrated into a numerical optimization tool.

This approach differs from others in the literature by defining the objective function as the minimization of irreversibilities, subjected to the thermodynamic constraints of cycle. The optimal plant configuration is defined, as well as, the amount of exergy that is lost at each one of the five system components. The numerical model was run in MatLab® environment, through its optimization toolbox. The level of exergy destruction, and the extent and sources of thermodynamic inefficiencies in thermal system are investigated. A sensitivity analysis of operating parameters of the system is also presented.

\section{CHP PLANT DESCRIPTION}

This study is based on a small-scale cogeneration system operating under the Joule-Brayton cycle. This is sized to deliver $125 \mathrm{~kW}$ of thermal power to fulfill the base heating load of a medium-size building. Figure 1 illustrates the layout of a micro turbine based CHP system. The turbo machinery and the electric generator are connected to a common shaft rotating at high speed. An inverter couples the high frequency current produced to the grid which enables variable speed operation. For such applications, micro gas turbines require an internal air pre-heater (IPH) or regenerator, to provide a satisfactory electrical efficiency. The thermal energy of the exhaust gases is recovered as heat.

Air is compressed (C) and fed to the regenerator (IPH) before entering the Combustion Chamber (CC) where it is mixed with natural gas.

High temperature expansion of the combustion gases occurs in the Turbine (T). The Exhaust Gases (EG) leaving the turbine are used to pre-heat the incoming air in the IPH and subsequently for the production of hot water in the external heat recovery system, before exiting to the atmosphere. The latter is a Water Heat Exchanger (WHE), where a constant mass flow rate of water is heated from $313 \mathrm{~K}$ to $353 \mathrm{~K}$.

These temperatures were assumed by considering that water circulates in a closed loop, where the thermal loads results from the cold water from the grid supply and the return 
water from the heating system. The system runs on commercial Natural Gas (NG) with a Low Heating Value (LHV) of 47,763 $\mathrm{kJ} / \mathrm{kg}$.

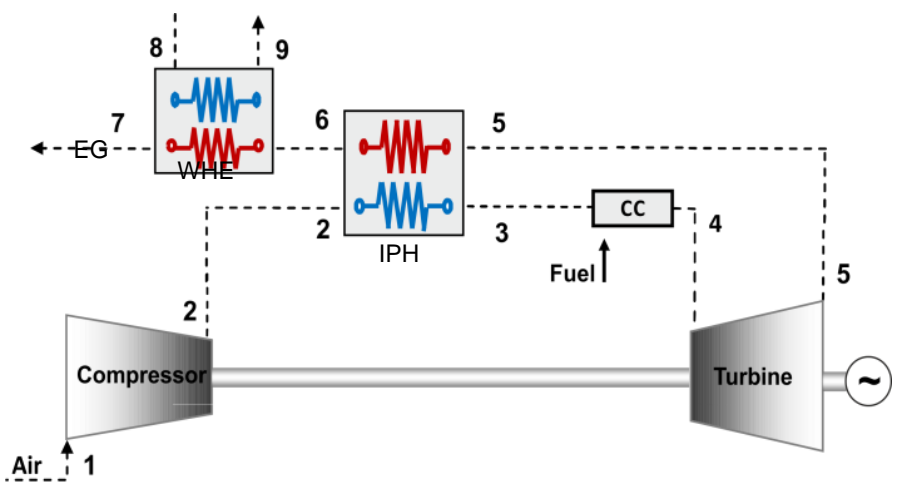

Figure 1. Schematic representation of the micro gas
turbine CHP system.

Table 1 summarizes the main technical specifications of the components used in the present model.

Table 1 Fixed specification for model calculations.

\begin{tabular}{cc}
\hline \multicolumn{2}{c}{ Design specifications for calculations } \\
\hline Electromechanical efficiency & $93 \%$ \\
Fuel combustion efficiency & $98 \%$ \\
IPH air-side pressure loss & $5 \%$ \\
IPH gas-side pressure loss & $5 \%$ \\
Thermal Power load & $125 \mathrm{~kW}$ \\
\hline
\end{tabular}

\section{MATHEMATICAL MODEL}

In this section, the optimization model and its mathematical formulation are presented. This model includes the definition of the objective function and problem constraints, the identification of the decision variables, and also the optimization algorithm used to reach the optimal solution.

\section{Formulation of Exergy-Rate Balance Equations}

Irreversibility can be used to assess the magnitude and the source of thermodynamic inefficiencies in a thermal system. Therefore, the exergy analysis enables the calculation of the efficiency of the system components, by quantifying the entropy generated by each one of the components [21].

Exergy, by definition, is the maximum useful work that can be obtained from a system at a given state. Exergy accounts for the irreversibility of a process due to entropy production. Exergy is always destroyed in any process and such reduction is proportional to the entropy increase of the system and its environment [13,22,23]. Therefore, he inefficiency of a system can be measured by calculating the exergy destruction. The irreversibilities represent the wasted energy that could have been converted into useful work.
For any given component (Figure 2) the exergy fluxes can be described by a general balance equation.

The exergy-balance equations for each component can be derived from the general exergy balance Eq. (1).

$$
\dot{E}_{\text {in }}+\dot{E}^{Q}=\dot{E}_{\text {out }}+\dot{E}^{W}+\dot{I}
$$

where the terms with the subscripts in and out denote, respectively, inlet and outlet exergy associated to the mass flows [21]. Terms with the superscripts $Q$ and $W$ represent the positive cross-boundary thermal and work components of exergy, respectively. The term $\dot{I}$ represents the rate of exergy destruction or irreversibility rate at each system component.

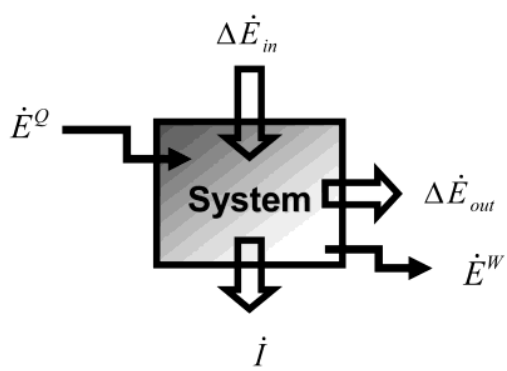

\section{Figure 2. Schematic representation of an exergy balance for a system.}

Exergy associated with mass flow can be divided into two main components: physical and chemical exergy.

Physical exergy $\left(\dot{E}_{p h}\right)$ is evaluated in terms of pressure $(P)$ and temperature $(T)$, when a system returns to NPT conditions through reversible processes, such as described in Eq. (2):

$$
\dot{E}_{p h}=\dot{m}\left[\left(H-H_{0}\right)-T_{0}\left(S-S_{0}\right)\right]
$$

where $\dot{m}$ is the mass flow rate, $\left(H-H_{0}\right)$ is the enthalpy variation and $\left(S-S_{0}\right)$ is the entropy variation relatively to the reference conditions. Therefore for an ideal gas the physical exergy can be calculated according to Eq. (3):

$$
\dot{E}_{p h}=\dot{m}\left[c_{p}\left(T-T_{0}\right)-T_{0}\left(c_{p} \ln \frac{T}{T_{0}}-\bar{R} \ln \frac{P}{P_{0}}\right)\right]
$$

where $T$ and $P$ are the temperature and pressure at a specific stage in the plant, $T_{0}$ and $P_{0}$ the reference conditions, $\bar{R}$ the gas constant and $c_{p}$ the heat capacity [24].

To simplify the calculations, average specific heat capacities were assumed. The mean values were evaluated for each fluid (i.e. air, combustions gases) for a temperature interval lying between the standard temperatures, $T_{0}$, and the gas temperature, $T$. The mean heat capacity data was obtained from Kotas [21] and is defined according to Eq. (4):

$$
\bar{c}_{p}=\frac{1}{T-T_{0}} \int_{T_{0}}^{T} c_{p}(T) d T
$$

where $c_{p}(T)$ is a polynomial function. 
Chemical exergy $\left(\dot{E}_{c h e}\right)$ represents the maximum amount of work obtainable when a substance is brought from the environmental stage to the dead stage, by processes involving heat transfer and exchange of substances. Calculation of the chemical exergy for fuels is complex because they are not part of the system of common reference substances in the atmosphere and additional equations for chemical reactions must be included. Also the respective fraction of each reference substance at the mixture shall be considered. Therefore, the chemical exergy can be calculated through Eq. (5):

$$
\dot{E}_{c h e}=\frac{\dot{m}}{M}\left(\sum X_{i} \varepsilon_{i}+\tilde{R} T_{0} \sum X_{i} \ln X_{i}\right)
$$

where $\tilde{R}$ represents the ideal gas constant, $X_{i}$ is the volumetric fraction of the $i$-th component, $\varepsilon_{i}$ is the molar chemical exergy of each substance and $M$ is the molar mass of the mixture (i.e. fuel or flue gases).

\section{Objective Function}

The objective function is defined as the minimization of the overall irreversibilities of the system, as Eq. (6):

$$
\operatorname{Min}\left(\dot{I}_{C}+\dot{I}_{C C}+\dot{I}_{T}+\dot{I}_{I P H}+\dot{I}_{W H E}+\dot{I}_{E G}\right)
$$

where $I$ is the rate of exergy destruction in each one of the system components. The subscripts correspond to those referred in Figure 1. The exergy-balance equations for each system component, described elsewhere [25], are summarized and presented in Table 2 (Eq. 7-14).

The model was developed considering the system components as adiabatic. Also, the mass and energy conservation laws were applied to each system component and they are detailed in [26].

For the compressor, $\dot{E}_{1}$ and $\dot{E}_{2}$ correspond to the inlet and outlet exergy rates, respectively, and $w_{C}$ is the specific work done during the adiabatic compression of an air mass flow rate, where $c_{p_{\text {air }}}$ is the average specific heat of the air, $T_{2}$ the compressor outlet temperature and $T_{1}$ the air inlet temperature. The reference temperature is assumed to be $293 \mathrm{~K}$, and the specific ideal gas constant of $287.1 \mathrm{~J} / \mathrm{kgK}$.

For the Turbine, $\dot{E}_{4}$ and $\dot{E}_{5}$ correspond to the inlet and outlet exergy rates, respectively, and $w_{T}$ is the adiabatic expansion work of the combustion exhaust gases.

For the IPH, $\dot{E}_{2}$ and $\dot{E}_{3}$ correspond to the inlet and outlet exergy rates of the cold stream in the heat exchanger and, while $\dot{E}_{5}$ and $\dot{E}_{6}$ are the inlet and outlet exergy rates of the hot stream. In this study, the heat losses to environment are neglected.

The chemical exergy of the fuel accounts for the chemical reaction to convert the fuel that reacts with the oxygen in the air, into one or more reference substances $\left(\mathrm{CO}_{2}\right.$ and $\left.\mathrm{H}_{2} \mathrm{O}\right)$. The corresponding exergy associated to the natural gas was found to be $49,583.3 \mathrm{~kJ} / \mathrm{kg}$, based on the actual fuel composition of the gas utility and the exergy of each fuel component. The exergy for the reference substances used in the calculations were obtained from literature [21].

Table 2 Summary of exergy-balance equations for each CHP plant component and exhaust gases.
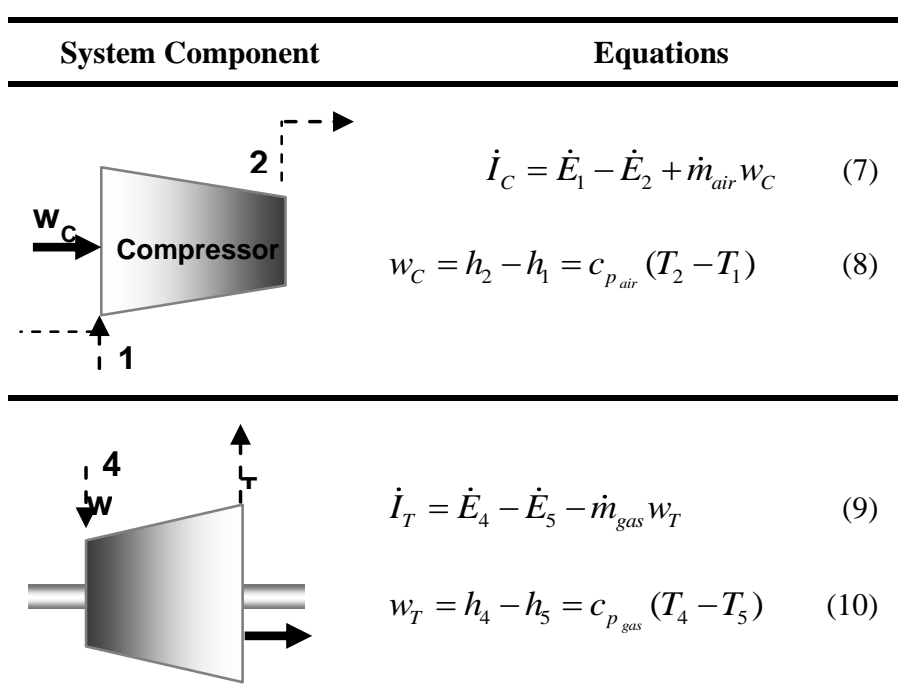

$$
\begin{aligned}
& 3 \quad \dot{I}_{C C}=\dot{E}_{p h_{\text {air }}}+\dot{E}_{c h e_{\text {air }}}+\dot{E}_{p h_{\text {fuel }}}+ \\
& \stackrel{3 \mathrm{cC}-1}{-1}+\dot{E}_{\text {che fiul }}-\dot{E}_{c h e_{\text {gas }}}-\dot{E}_{p h_{\text {gas }}}
\end{aligned}
$$

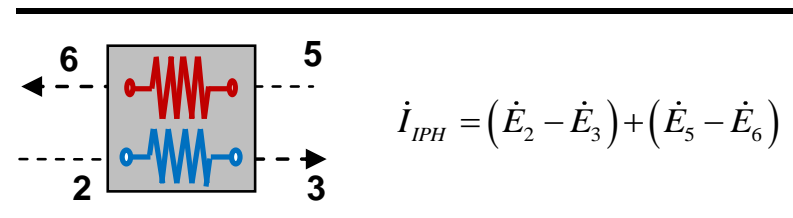

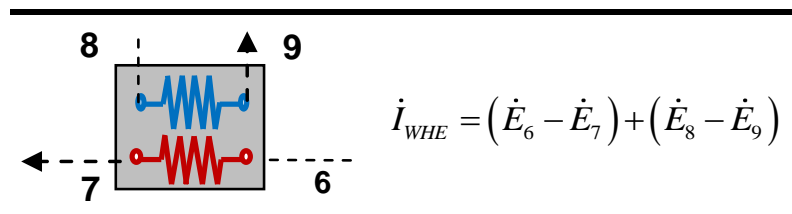

$$
T_{0}<-f_{0}-\dot{I}_{E G}=\left(\dot{E}_{7}-\dot{E}_{0}\right)+\dot{E}_{c h e_{\text {gas }}}
$$

Also, the chemical exergy of the exhaust gases from the combustion process is calculated by considering the volumetric fraction of the $p$-th component in the mixture. For this purpose a complete reaction was assumed. The exergybalance equation for the WHE corresponds to the equilibrium between the exergy variation of the hot and cold streams of the heat exchanger, respectively.

The EG exiting the system are not in equilibrium with the dead state. Therefore, an additional region must be included in the analysis to take into account the external irreversibilities resulting from this mixing process. 
In those, the exergy loss from gases to the environment includes the latent heat in the gases and the chemical exergy of the products, also shown in Table 2. In fact, minimizing the exergy loss in the exhaust gases could improve the overall rational efficiency of the CHP system.

\section{Constraints Definition}

Eighteen inequality constraints were formulated in order to give physical significance to the mathematical model. These constraints bound the variables within feasible limits of the system operation. For instance, the inlet temperature of the air $\left(T_{1}\right)$ is lower than the air temperature at IHP inlet $\left(T_{2}\right)$. The turbine inlet temperature $\left(T_{4}\right)$ is the highest temperature reached in the system. The high-pressure air is pre-heated upstream the $\mathrm{CC}$, and hence, it is required that the temperatures $\left(T_{2}\right)$ and $\left(T_{3}\right)$ are lower than that of the exhaust gases $\left(T_{5}\right)$.

The difference between the inlet and outlet temperatures in each heat exchanger flow should be limited to ensure the effectiveness heat transfer process between the fluids. In order to allow an effective heat transfer in the IPH and in the WHE, lower and upper limits were defined to guarantee a temperature differential between the two streams. Moreover, it is also important to make sure that the gas exit temperature $\left(T_{7}\right)$ is above $363 \mathrm{~K}$ in order to prevent condensation in the heat recuperating system.

Besides the constraints related to the temperature variation in the system, the Primary Energy Saving (PES) was also include in the model as an inequality constraint in order to guarantee that the system may be rated as high efficient CHP power plant [3]. According to the European legislation, smallscale cogeneration systems are high efficient if PES index is higher than $10 \%$.

Such constraints will prevent a null pinch solution where entropy minimization could be obtained by not running the facility.

\section{Decision Variables}

Six decision variables were selected due to their relevance: the compressor pressure ratio $\left(r_{C}\right)$; the isentropic efficiency of the compressor $\left(\eta_{C}\right)$; and of the turbine $\left(\eta_{T}\right)$; the air temperature at the internal pre-heater $\left(T_{3}\right)$; the temperature of the combustion gases at the turbine inlet $\left(T_{4}\right)$; and the electrical power production $(\dot{W})$. The simulation was performed considering simple bounds for the decision variables, as defined by the Eqs. (15-20):

$$
\begin{gathered}
3.0 \leq r_{C} \leq 6.0 \\
0.80 \leq \eta_{C} \leq 0.86 \\
850 \leq T_{3} \leq 950 \\
0.80 \leq n_{T} \leq 0.88
\end{gathered}
$$

$$
\begin{gathered}
1000 \leq T_{4} \leq 1400 \\
90 \leq \dot{W} \leq 110
\end{gathered}
$$

Typical bounds, for the electrical power (Eq. (20)), were based on the range of the heat-to-power ratios found in such systems, which defines the relationship between the amount of useful heat and the electricity produced.

\section{Numerical Solution}

In the study herein, a local optimization method, the Sequential Quadratic Programming method (SQP), is used in order to solve the constrained optimization problem. SQP [17] is one of the most successful methods for the numerical solution of constrained nonlinear optimization problems. It provides a powerful algorithmic tool for the solution of optimization problems. The idea of SQP is to model the constrained nonlinear problem by a quadratic sub-problem and to use the solution of this sub-problem to find an approximation to the solution of the original problem. SQP is an application of Newton's method considering the Karush-Kuhn-Tucker optimality conditions. In this sense, the nonlinear problem resembles the Newton and quasi-Newton methods for the numerical solution of nonlinear systems of algebraic equations [27].

This method requires the definition of an initial point to start the algorithm. The algorithm was run by using the optimization toolbox of MatLab®, through the Fmincon routine. The initial approximation for the six decision variables were given by: $r_{C}=4.0 ; \eta_{C}=\eta_{T}=0.85 ; T_{3}=850 \mathrm{~K} ; T_{4}=1,200 \mathrm{~K}$ and $\dot{W}=100 \mathrm{~kW}$.

\section{RESULTS \& DISCUSSION}

The convergence criterion was defined at $1.0 \mathrm{E}-10$ for both the objective function and for constraint violation. The simulation converged after 29 iterations and 209 evaluations of the objective function. The optimal solution was found and the objective function converged to a local minimum. The convergence process was found to be independent of the initial approximation. Table 3 shows the optimal values for the six decision variables, which correspond to the optimal CHP plant configuration. The results show the plant configuration that minimizes the irreversibilities corresponds to a micro-gas turbine working with a compressor pressure ratio of 4.145 . This value is close to that currently available in the market for micro-gas turbines which, for a single-stage compression, is approximately 4 .

The compressor and turbine efficiencies are $86 \%$ and $88 \%$, respectively. The compressor and the turbine irreversibilities are directly related with their isentropic efficiency. Therefore, it is reasonable that the optimization solution will converge to the upper bounds of these variables. It is also observed that the air temperature at the internal pre-heater $\left(T_{3}\right)$ equals the upper limit for this variable in the model. 
Table 3 Optimum values for decision variables.

\begin{tabular}{cc}
\hline \multicolumn{2}{c}{ Decision Variables } \\
\hline$r_{C}$ & 4.145 \\
$\eta_{C}(\%)$ & 86.0 \\
$\eta_{T}(\%)$ & 88.0 \\
$T_{3}(\mathrm{~K})$ & 950.0 \\
$T_{4}(\mathrm{~K})$ & 1266.8 \\
$\dot{W}(\mathrm{~kW})$ & 99.56 \\
\hline
\end{tabular}

According to Kaiko and Backman [9], the turbine inlet temperature of micro-gas turbines, typically, varies between $1,070-1,270 \mathrm{~K}$. In this study, it was obtained a TIT of $1,266.8$ $\mathrm{K}$, which is within the reference range.

In addition, for this configuration, the system is able to produce $99.56 \mathrm{~kW}_{\mathrm{e}}$ assuming a generator efficiency of $93 \%$.

Apart from the compression pressure ratio and TIT, one of the most important parameters in micro-gas turbines is the IPH effectiveness. The IPH is used in micro-gas turbines in order to improve the system efficiency by recovering additional heat from the exhaust gases. For the optimal solution, an IPH effectiveness (defined as the ratio between the heat recovered by the cold stream and the maximum heat available) of $95.6 \%$ was calculated. This component is of paramount importance to improve the overall efficiency of gas turbine, particularly for those operating with low compressor ratios. One possible conclusion is that high efficiencies in the IPH and compressor/turbine are crucial for overall plant performance.

From the operation data, the electrical efficiency was also calculated, being obtained a value of $33 \%$. Both values are high when compared to those often found in commercial models: an IPH effectiveness of $90 \%$ and an electrical efficiency within 25 to $31 \%$ [26]. The system overall efficiency is $80.04 \%$ (based on LHV).

Overall the optimal configuration obtained by the present exergy minimization procedure is similar to that obtained by the authors for the same input conditions following a thermoeconomic optimization based on the first law, as described elsewhere [26]. This is also due to the non-linear constraints imposed in model which limit the evolution of thermodynamic variables.

Table 4 summarizes the results concerning some of the thermodynamic properties.

Table 4 Thermodynamic properties along the cycle.

\begin{tabular}{cc|cc}
\hline \multicolumn{2}{c|}{ Temperature $(\boldsymbol{K})$} & \multicolumn{2}{c}{ Pressure $(\boldsymbol{k P a})$} \\
\hline$T_{2}$ & 463.7 & $P_{2}$ & 419.85 \\
$T_{5}$ & 972.1 & $P_{3}$ & 398.85 \\
$T_{6}$ & 553.0 & $P_{4}$ & 378.91 \\
$T_{7}$ & 367.7 & $P_{5}$ & 109.93 \\
& & $P_{6}$ & 106.63 \\
\hline
\end{tabular}

The total plant irreversibility was calculated as $170.54 \mathrm{~kW}$. Figure 3 shows the Grassmann diagram depicting the exergy losses through the plant. Figure 3 presents an exergy rate output of $99.56 \mathrm{~kW}$ in the form of useful work and $14.88 \mathrm{~kW}$ in the form of hot water in the external exchanger. From the results, it can be said that the $\mathrm{CC}$ destructs the largest amount of the total inlet exergy into the plant, which is provided by the fuel, at a rate of $281.26 \mathrm{~kW}$ of useful exergy. In fact, two highly irreversible processes (combustion and high gradient heat transfer) occur in this component. This observation is in agreement with other authors [15].

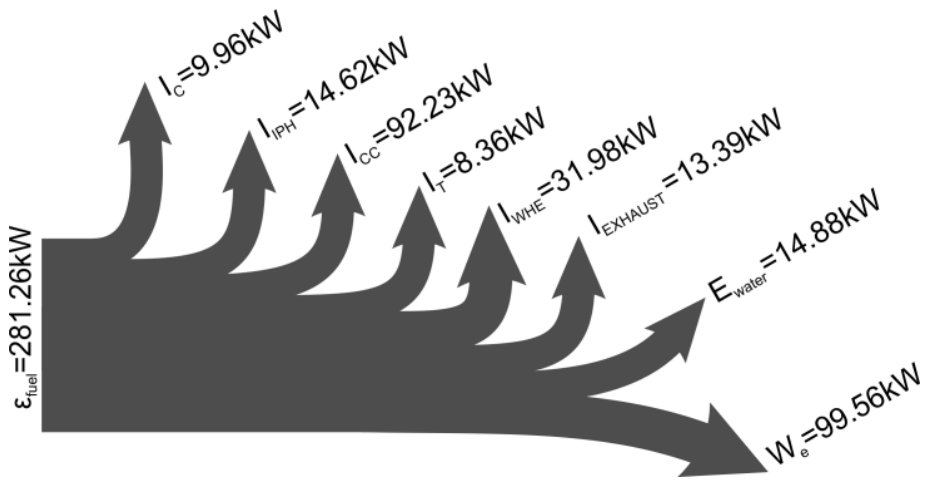

Figure 3: Grassmann diagram depicting the exergy losses.

The WHE is the plant component where the second highest amount of exergy is wasted. This may be due to the fact that high temperature energy is converted to low temperature heat. A sensitivity analysis should be performed in order to study the influence of heating water temperature in the WHE exergetic efficiency.

Also, the external irreversibilities (nearly $13.4 \mathrm{~kW}$ ) are a major contribution to the plant inefficiency. This outcome may be related with the model assumptions for the physical system. As previous mentioned, the exhaust temperature $\left(T_{7}\right)$ was lower bounded in order to prevent condensation in the heat recuperating system.

The rational efficiency of the plant is a measure of plant performance and it is defined by the ratio of useful exergy output and the maximum input exergy, as Eq. (21):

$$
\psi=\frac{\sum \Delta \dot{E}_{\text {out }}}{\sum \Delta \dot{E}_{\text {in }}}
$$

The rational efficiency was also calculated for each plant component and results are presented in Figure 4.

The overall rational efficiency of the plant is $40.73 \%$. The Turbine is the system component with highest exergetic efficiency (approximately 96\%) followed by the compressor and the IPH.

Although the combustion chamber shows the highest destruction of total exergy, the WHE is the component with lowest efficiency (41\%).

In fact, there is a high degradation of the energy in WHE, where the available energy is converted into low temperature water. 


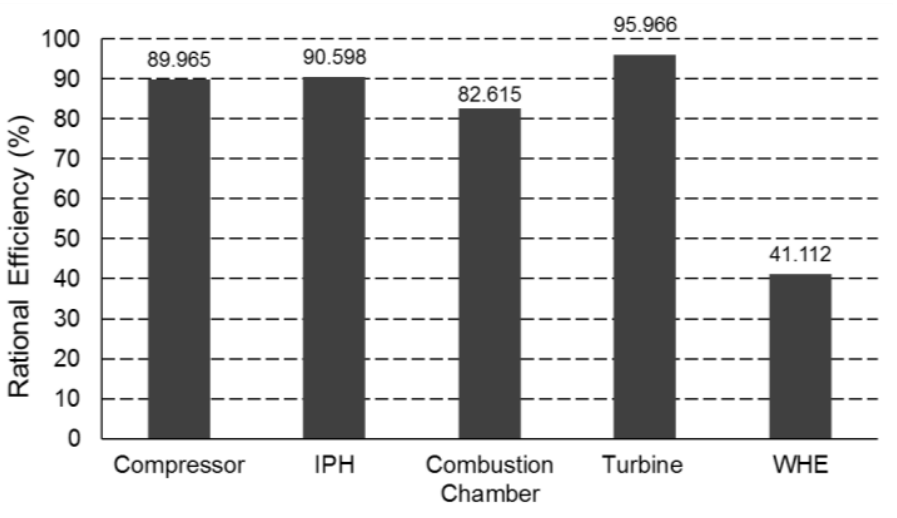

Figure 4: Rational efficiency of system components.

\section{Sensitivity Analysis}

A sensitivity analysis was carried out in order to analyze the influence of TIT upon the exergy destruction and rational efficiency. The evaluation was performed considering the optimal operating parameters for three of the decision variables ( $r_{C}$ of $4.133, \eta_{C}$ of $86 \%$ and $\eta_{T}$ of $88 \%$ ). Figure 5 shows the influence of the gas turbine inlet temperature on the total exergy efficiency. For the calculations, a range between 1,100 $\mathrm{K}$ and $1,300 \mathrm{~K}$ for the TIT value was considered. It shows that an increase in TIT leads to an increase in the rational efficiency due to the fact that turbine work output increases. Also, Figure 5 confirms that an increase in the TIT leads to a reduction in exergy destruction. It should be noted that by fixing only 3 out of the 6 decision variables, when varying on of these (TIT), the other two $\left(T_{3}\right.$ and $\left.W\right)$ are free to change. It results that if the irreversibility drops below the minimum (for TIT above $1,266.8 \mathrm{~K}$ ) the other two are outside the boundaries defined for the problem. Therefore the optimal solution (table 3) is in fact a minimum.

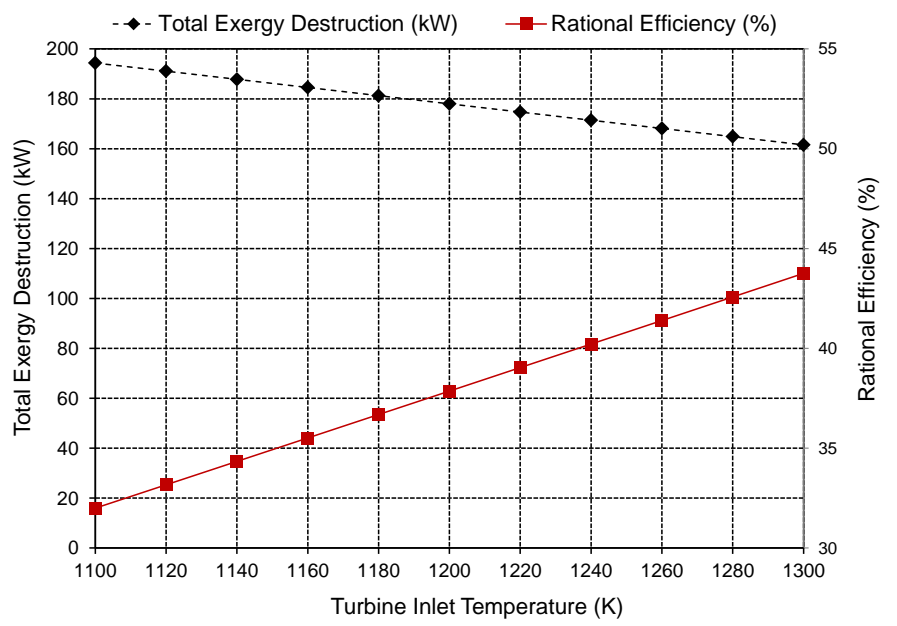

Figure 5: Influence of TIT variation in rational
efficiency.

Another important aspect to consider in the analysis is the air inlet temperature $\left(T_{1}\right)$. The effect of compressor air inlet temperature on exergy destruction, power output and exergy efficiency of each system component is presented in Table 5.

The total exergy destruction of the plant increases from $169.6 \mathrm{~kW}$ to $174.2 \mathrm{~kW}$. This results in an increase of about 30 $\mathrm{W}$ of exergy destruction per degree of temperature increase.

The total exergy efficiency decreases with increasing the ambient temperature. For instance, the total exergy efficiency of the plant decreases from $40.93 \%$ to $38.94 \%$ for an ambient temperature variation of $15 \mathrm{~K}$. The combustion chamber is the component whose efficiency is most sensitive to the ambient temperature. The exergy efficiencies of the compressor, IPH, combustion chamber, turbine and WHE also decreased with increasing $T_{1}$. Results show that the WHE is the component with the lowest exergy efficiency, decreasing by approximately $13 \%$, while the compressor, IPH, combustion chamber and turbine efficiencies decrease by $0.33 \%, 0.7 \%, 0.9 \%$ and $0.2 \%$, respectively.

Table 5 Calculated performance data based on exergy analysis considering different values of $T_{1}$.

\begin{tabular}{|c|c|c|c|c|}
\hline & \multicolumn{4}{|c|}{$T_{1}(\mathbf{K})$} \\
\hline & 290 & 295 & 300 & 305 \\
\hline Exergy Destruction at $\mathrm{C}(\mathrm{kW})$ & 8.75 & 8.91 & 9.02 & 9.07 \\
\hline Exergy Destruction at IPH $(\mathrm{kW})$ & 14.05 & 14.29 & 14.53 & 14.77 \\
\hline Exergy Destruction at $\mathrm{CC}(\mathrm{kW})$ & 93.09 & 94.27 & 95.46 & 96.64 \\
\hline Exergy Destruction at $\mathrm{T}(\mathrm{kW})$ & 8.25 & 8.39 & 8.54 & 8.68 \\
\hline Exergy Destruction WHE (kW) & 31.65 & 32.19 & 32.74 & 33.28 \\
\hline Total Exergy Destruction (kW) & 169.6 & 171.1 & 172.7 & 174.2 \\
\hline Power Output (kW) & 99.56 & 99.56 & 99.56 & 99.56 \\
\hline Total Exergy Efficiency (kW) & 40.93 & 40.27 & 39.60 & 38.94 \\
\hline Exergy Efficiency C (\%) & 91.04 & 90.88 & 90.77 & 90.71 \\
\hline Exergy Efficiency IPH (\%) & 90.86 & 90.63 & 90.40 & 90.16 \\
\hline Exergy Efficiency CC (\%) & 82.41 & 82.11 & 81.81 & 81.51 \\
\hline Exergy Efficiency T (\%) & 95.98 & 95.92 & 95.85 & 95.78 \\
\hline Exergy Efficiency WHE (\%) & 43.48 & 39.49 & 35.25 & 30.75 \\
\hline
\end{tabular}

Figure 6 shows the effect of the compressor pressure ratio and isentropic efficiency on the total exergy destruction. It is shown that a higher pressure ratios leads to lower exergy destruction in the whole cycle.

By increasing the pressure ratio more useful work is delivered by the plant. Furthermore the increase in isentropic efficiency reduces the frictional losses of the compressor and the overall efficiency of the plant. 


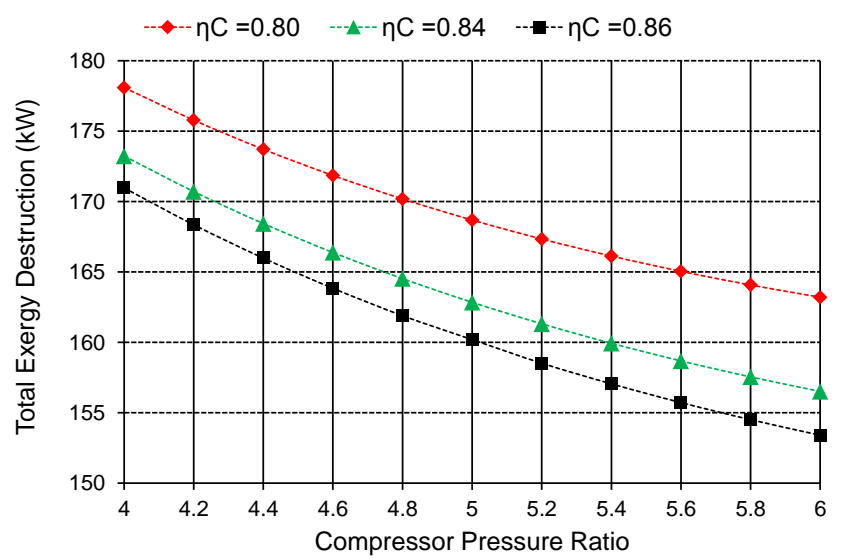

Figure 6: Effect of compressor pressure ratio on the exergy destruction.

\section{CONCLUSIONS}

In this study, the first and the second law of thermodynamics were combined to evaluate the efficiency of a gas turbine cogeneration system. The quality and performance of internal components are included as decision variables. This was done by integrating a full thermodynamic model, considering the physical parameters in the definition of the optimization model, and using the first and the second law of thermodynamics.

A gradient based optimization method was applied to minimize the exergy destruction for a small-scale cogeneration system, based on micro-gas turbine technology. The simulation algorithm was applied in MatLab® environment, through the optimization toolbox.

The optimal solution was obtained considering as the objective function the minimization of the irreversibilities for each component and the irreversibility of the exhaust gases. Regarding the physical model, the most relevant and susceptible variables are the compressor pressure ratio and the turbine inlet temperature.

The exergy balance applied to a process (or a whole power production plant) expresses the amount of usable work potential (or exergy) supplied as the input to the system that has been consumed by its operation. The loss of exergy provides a quantitative measure of process inefficiency. The results showed that considerable exergy destruction occurs in the combustion chamber, which is due to the chemical reaction and the large difference of temperature between the primary zone of the burner and the exiting working fluid, after dilution with air.

The WHE is the system component with lower rational efficiency. A possible explanation is related with the high degradation of the energy in this exchanger that results from converting the available energy into low temperature heat.

In brief, the optimal sizing of micro-gas turbines has a dynamic role in their overall economic viability: decreasing the size typically increases the specific cost of the equipment. As future work, the cost of exergy destruction will be included in the analysis.

\section{NOMENCLATURE}

$\begin{array}{ll}c_{p} & \text { Specific Heat, } \mathrm{kJ} / \mathrm{kgK} \\ \dot{E} & \text { Rate of Exergy flow, } \mathrm{kW} \\ H & \text { Enthapy, } \mathrm{kJ} / \mathrm{kg} \\ L H V & \text { Low Heating Value, } \mathrm{kJ} / \mathrm{kg} \\ \dot{m} & \text { Mass flow rate, } \mathrm{kg} / \mathrm{s} \\ N G & \text { Natural Gas, }(-) \\ P & \text { Pressure, bar } \\ \dot{Q} & \text { Thermal Power, } \mathrm{kW} \\ r & \text { Compression ratio, (-) } \\ R & \text { Gas Constant, J/kgK } \\ \dot{S} & \text { Entropy flow rate, } \mathrm{kW} / \mathrm{K} \\ t & \text { Time, } \mathrm{s} \\ T & \text { Temperature, } \mathrm{K} \\ T_{0} & \text { Reference Ambient Temperature, } \mathrm{K} \\ T I T & \text { Turbine Inlet Temperature, } \mathrm{K} \\ \dot{W} & \text { Electrical power, } \mathrm{kW}\end{array}$

\section{Greek symbols}

$\varepsilon \quad$ chemical exergy of the substance, $\mathrm{kJ} / \mathrm{mol}$

$\eta \quad$ efficiency

\section{Subscripts}

$\begin{array}{ll}\text { 1-9 } & \text { system state points } \\ \text { air } & \text { Air } \\ C & \text { Compressor } \\ \text { CC } & \text { Combustion chamber } \\ \text { che } & \text { Chemical } \\ \text { EG } & \text { Exhaust gases } \\ e & \text { electrical } \\ \text { fuel } & \text { fuel } \\ \text { gas } & \text { gas } \\ \text { in } & \text { inlet } \\ \text { IPH } & \text { Internal Pre-Heater } \\ \text { out } & \text { outlet } \\ p & \text { combustion products } \\ \text { ph } & \text { physical exergy } \\ T & \text { Turbine } \\ \text { WHE } & \text { Water Heat Exchanger }\end{array}$

\section{Superscripts}

$Q \quad$ thermal component of exergy

W $\quad$ work component of exergy 


\section{ACKNOWLEDGMENTS}

The authors would like to express their acknowledgments for the support given by the Portuguese Foundation for Science and Technology (FCT) through the PhD grant SFRH/BD/62287/2009. This work was financed by National Funds-Portuguese Foundation for Science and Technology, under Strategic Project and PEst-OE/EME/UI0252/2011 and also the PEst-C/EME/UI4077/2011.

\section{REFERENCES}

[1] G. Angrisani, C. Roselli, M. Sasso, Distributed microtrigeneration systems, Progress in Energy and Combustion Science. 38 (2012) 502-521.

[2] H.I. Onovwiona, V.I. Ugursal, Residential cogeneration systems: review of the current technology, Renewable and Sustainable Energy Reviews. 10 (2006) 389-431.

[3] DIRECTIVE 2004/8/EC - Directive on the promotion of cogeneration based on a useful heat demand in the internal energy market, European parliament and the council of the european union, 2004.

[4] M. Valdés, M.D. Durán, A. Rovira, Thermoeconomic optimization of combined cycle gas turbine power plants using genetic algorithms, Applied Thermal Engineering. 23 (2003) 2169-2182.

[5] X.Q. Kong, R.Z. Wang, X.H. Huang, Energy optimization model for a CCHP system with available gas turbines, Applied Thermal Engineering. 25 (2005) 377-391.

[6] A. Datta, R. Ganguly, L. Sarkar, Energy and exergy analyses of an externally fired gas turbine (EFGT) cycle integrated with biomass gasifier for distributed power generation, Energy. 35 (2010) 341-350.

[7] P. a. Pilavachi, Mini- and micro-gas turbines for combined heat and power, Applied Thermal Engineering. 22 (2002) 2003-2014.

[8] Energy and Environmental Analysis, Technology Characterization: Microturbines, Energy and Environmental Analysis ICF International Company, Arlington, Virginia, 2008.

[9] J. Kaikko, J. Backman, Technical and economic performance analysis for a microturbine in combined heat and power generation, Energy. 32 (2007) 378-387.

[10] J. Kaikko, J. Backman, L. Koskelainen, J. Larjola, Technical and economic performance comparison between recuperated and non-recuperated variable-speed microturbines in combined heat and power generation, Applied Thermal Engineering. 27 (2007) 2173-2180.

[11] F.I. Abam, I.U. Ugot, D.I. Igbong, Effect of Operating Variables on Exergetic Efficiency of an, Journal of Emerging Trends in Engineering and Applied Sciences (JETEAS) 3. 3 (2012) 131-136.
[12] E. Bilgen, Exergetic and engineering analyses of gas turbine based cogeneration systems, Energy. 25 (2000) 1215-1229.

[13] W. Hussein, A. Razzaq, Exergy Analysis of a Gas Turbine Performance with effect cycle temperatures, International Journal of Research and Reviews in Applied Sciences. 13 (2012) 549-556.

[14] H. Feng, L. Chen, F. Sun, Exergoeconomic optimal performance of an irreversible closed Brayton cycle combined cooling, heating and power plant, Applied Mathematical Modelling. 35 (2011) 4661-4673.

[15] P. Ahmadi, I. Dincer, Thermodynamic and exergoenvironmental analyses, and multi-objective optimization of a gas turbine power plant, Applied Thermal Engineering. 31 (2011) 2529-2540.

[16] A. Erdil, Exergy optimization for an irreversible combined cogeneration cycle, Journal of the Energy Institute. 78 (2005) $27-31$.

[17] M.A. Rodríguez-Toral, W. Morton, D.R. Mitchell, Using new packages for modelling, equation oriented simulation and optimization of a cogeneration plant, Computers \& Chemical Engineering. 24 (2000) 2667-2685.

[18] G. Tsatsaronis, Thermoeconomic analysis and optimization of energy systems, Progress in Energy and Combustion Science. 19 (1993) 227-257.

[19] A. Valero, M.A. Lozano, L. Serra, G. Tsatsaronis, J. Pisa, C. Frangopoulus, et al., CGAM Problem: Definition and Conventional Solution, Energy. 19 (1994) 279-286.

[20] L.B. Martins, A.C.M. Ferreira, M.L. Nunes, C.P. Leão, S.F.C.F. Teixeira, F. Marques, et al., Optimal Design of Micro-Turbine Cogeneration Systems for the Portuguese Buildings Sector, in: ASME (Ed.), Proceedings of the ASME 2011 International Mechanical Engineering Congress \& Exposition, ASME, Denver, 2011: pp. 179-186.

[21] T.J. Kotas, Exergy Analysis of Simple processes, in: The Exergy Method of Thermal Plant Analysis, Anchor Brendon Ldt, 1985: pp. 99-150.

[22] P.P. Oliveira, Fundamentos de Termodinâmica Aplicada, $1^{\text {a }}$ Edição, LIDEL Edições Técnicas. Lda, Lisboa, 2012.

[23] J. Szargut, D.R. Morris, F.R. Steward, Exergy analysis of thermal, chemical and metallurgical processes, Hemisphere Publishing Corporation, 1988.

[24] A. Bejan, G. Tsatsaronis, M. Moran, Thermal Design and Optimization, Wiley, Wiley, New York, 1996.

[25] A. Ferreira, L. Nunes, S. Teixeira, A. Silva, L. Martins, J. Teixeira, Tecno-Economic and Exergy Analysis of a SmallScale CHP Unit Based on a Micro-gas Turbine, in: MICROGEN 3 -International Conference on Microgeneration and Related Technologies, 2013. 
[26] A.C.M. Ferreira, M.L. Nunes, S.F.C.F. Teixeira, C.P. Leão, Â.M. Silva, J.C.F. Teixeira, et al., An economic perspective on the optimisation of a small-scale cogeneration system for the Portuguese scenario, Energy. 45 (2012) 436-444.

[27] A.C.M. Ferreira, A.M.A.C. Rocha, S.F.C.F. Teixeira, M.L. Nunes, L.A.S.B. Martins, On Solving the Profit Maximization of Small Cogeneration Systems, ICCSA 2012 12th International Conference on Computational Science and Its Applications - Lecture Notes in Computer Science. 7335 (2012) 147-158. 